\title{
Capillary blood reference intervals for platelet parameters in healthy full-term neonates in China
}

\author{
Dongyan $\mathrm{Cui}^{1+}$, Yan Hou${ }^{2+}$, Ling Feng ${ }^{3}$, Guo Li ${ }^{4}$, Chi Zhang ${ }^{4}$, Yanli Huang ${ }^{5}$, Jiubo Fan ${ }^{6}$ and Qun Hu ${ }^{1 *}$ (D)
}

\begin{abstract}
Background: No consensus has been reached on capillary blood reference intervals for platelet parameters in fullterm neonates. We aimed to establish neonatal capillary blood reference intervals for platelet parameters and evaluate influences of sex, gestational age and postnatal age on platelet parameters.

Methods: This study was a prospective investigation and implemented in 594 healthy full-term neonates from 12 to $84 \mathrm{~h}$ of age, using SYSMEX XN-9000 haematology automatic analyser by means of capillary blood. Reference intervals for platelet parameters were defined by an interval of 2.5th -97.5 th percentiles.

Results: Capillary reference interval for platelet count was $(152-464) \times 10^{9} /$ L. No significance was found between sex-divided reference intervals for platelet parameters. The values of platelet count changed minimally across gestational age (37-41 weeks) and postnatal age (12-84 h). Reference intervals for other platelet parameters were affected by these factors to a different extent.
\end{abstract}

Conclusions: We established capillary blood reference intervals for platelet parameters in the first days after birth of full-term neonates in China.

Keywords: Neonates, Capillary blood, Platelet count, Platelet parameters, Reference intervals

\section{Background}

Reference intervals (RIs) play a critical role in clinical practice. Appropriate RIs for platelet parameters ensure clinical laboratories provide reliable information and enable clinicians to correctly interpret results and further determine whether transfusions are needed for neonates $[1,2]$. However, few normative data are available in RIs for platelet parameters in full-term neonates [3]

Neonates are in a crucial period of rapid development, and platelet parameters are significantly affected by these physiological changes [4]. Moreover, RIs for platelet

\footnotetext{
* Correspondence: qunhu2013@163.com

${ }^{\dagger}$ Dongyan Cui and Yan Hou contributed equally to this work.

'Department of Paediatric Haematology and Oncology, Tongji Hospital,

Tongji Medical College, Huazhong University of Science and Technology,

Wuhan 430030, Hubei Province, People's Republic of China

Full list of author information is available at the end of the article
}

parameters have often been derived from haematological results of both inpatient and outpatient neonates $[4,5]$, or blood samples are leftover material from the donated blood for a specific use in a pre-term (delivered at less than 37 weeks of gestation) or full-term neonate population $[6,7]$, which may be inaccurate and unreliable for full-term neonates. It is hard for neonatal health care providers to provide standard-of-care health services as a lack of appropriate RIs for haematology may impede diagnostics for neonates [8]. The study of RIs for platelet parameters in neonates is highly restricted due to the ethical limitations and difficulties to obtain sufficient blood samples. Capillary sampling by the automated incision device spends a shorter time for blood collection with reduced haemolysis [9], and is increasingly used in clinical practice nowadays in China. Capillary blood for

C C The Author(s). 2020 Open Access This article is licensed under a Creative Commons Attribution 4.0 International License, which permits use, sharing, adaptation, distribution and reproduction in any medium or format, as long as you give appropriate credit to the original author(s) and the source, provide a link to the Creative Commons licence, and indicate if changes were made. The images or other third party material in this article are included in the article's Creative Commons licence, unless indicated otherwise in a credit line to the material. If material is not included in the article's Creative Commons licence and your intended use is not permitted by statutory regulation or exceeds the permitted use, you will need to obtain permission directly from the copyright holder. To view a copy of this licence, visit http://creativecommons.org/licenses/by/4.0/ The Creative Commons Public Domain Dedication waiver (http://creativecommons.org/publicdomain/zero/1.0/) applies to the data made available in this article, unless otherwise stated in a credit line to the data. 
haematology tests is as small as necessary in volumes and as non-invasively as possible with a very low frequency of local infection and decreased extent of bruising [10]. Although capillary blood is used to develop RIs for other biologic markers [11-13], studies have not been carried out to evaluate its clinical utility in neonatal capillary blood RIs for platelet parameters.

Ideally, RIs for platelet parameters are established in a healthy full-term neonate population and more than 120 specimens are required by the Clinical and Laboratory Standards Institute (CLSI) [14]. The objectives of the present study were to determine capillary blood RIs for platelet count (PLT) and related parameters in 594 healthy full-term neonates from 12 to $84 \mathrm{~h}$ of age, and furthermore to evaluate influences of sex, gestational age and postnatal age on platelet parameters.

\section{Methods}

\section{Study populations}

The study commenced after obtaining Institutional Ethical Committee approval (TJ-IRB20190308). The subjects were prospectively enrolled into this study, and all of them were healthy full-term ( 259 to 293 days (37 to 41 weeks) of gestation) neonates born at two hospitals from November 2018 to April 2019. Major inclusion/exclusion criteria are listed as follows. As listed in Chang et al. [6] for mothers, maternal age ranged from 20 to 40 years old and they had a normal health check-up without unfavourable past history during pregnancy, such as smoking, infectious diseases (hepatitis $\mathrm{B} / \mathrm{C}$, HIV, syphilis infections), idiopathic thrombocytopenic purpura, malignancies and chronic diseases (diabetes mellitus, autoimmune disease, immunodeficiencies and thrombotic disorders); mothers did not receive aspirin during pregnancy; a vaginal delivery or caesarean section was event-free. Professional obstetricians were responsible for the data of this part. As listed in Chang et al. [6] and Wasiluk [15] for neonates, they fitted all clinical state criteria for full-term neonates; they were born with normal birth weight (2500-4000 g) appropriate for gestational age and normal Apgar score (8-10 points at $1-5 \mathrm{~min}$ of life); physical examinations of the subjects were normal without any signs of infection or congenital anomalies at the time of sampling. And we excluded all neonates with an unfavourable perinatal history of premature rupture of membrane more than $24 \mathrm{~h}$, abnormal placenta, placenta abruption, chorioamnionitis or meconium stain, or with a medical history of hospitalizing in the neonatal intensive care unit. All subjects are Han ethnicity.

\section{Blood sampling}

After written informed consent was obtained from a parent or guardian for all subjects, we collected about $70 \mu \mathrm{L}$ capillary whole blood of the subjects during the first 4 days of life (12 to $84 \mathrm{~h}$ old), by heel prick with the automated incision device into BD Microtainer tubes (spec, $0.5 \mathrm{~mL}$; Becton Dickinson and Company, USA) containing K2-ethylenediaminetetraacetic acid (EDTA) as an anticoagulant. Samples were obtained by experienced technicians at the same time of blood sampling for the screening of congenital hypothyroidism and phenylketonuria or the routine serum bilirubin in morning hours (1-2 h later after last food intake). The firstsecond drop of blood was discarded and each collection time was less than $1 \mathrm{~min}$. Samples were stored at ambient temperature for a maximum of $4 \mathrm{~h}$ before the assay was performed.

\section{Laboratory analyses}

All capillary blood samples were analysed by SYSMEX XN-9000 haematology automatic analyser (Sysmex Corporation, Kobe, Japan) in the pre-dilution mode (dilution ratio, complete blood: PK dilution $=1: 6$ ) to measure PLT $\left(\times 10^{9} / \mathrm{L}\right)$ and related parameters, including mean platelet volume (MPV, fL), plateletcrit level (PCT, \%), platelet size distribution width (PDW, fL) and platelet large cell ratio (P-LCR, \%). As listed in Kaito et al. [16] for the detection principle of platelet parameters, MPV was calculated by a formula (PCT / PLT $\times 10^{4}$ ), and PDW and PLCR were analysed from a histogram of platelet size distribution. Quality controls were run during every shift.

\section{Statistical analysis}

Data management and analyses were performed using SPSS 25.0 software (SPSS Inc., Chicago, USA). The data distribution was evaluated using Q-Q plots, histograms and Shapiro-Wilk test. We built Box plot (with Tukey variation) to identify the outliers using GraphPad Prism 8.2.1 (GraphPad software, La Jolla, CA, USA). An outlier was defined as a value $<\mathrm{Q}_{1}-1.5 \times \mathrm{IQR}\left(\mathrm{Q}_{1}: 25\right.$ th percentiles, IQR: interquartile range), or $>\mathrm{Q}_{3}+1.5 \times \mathrm{IQR}\left(\mathrm{Q}_{3}\right.$ : 75 th percentiles). Quantitative data were expressed as either mean ( \pm standard deviation, SD) for normally distributed data or median (IQR) for data not normally distributed. RIs for platelet parameters were defined by an interval of 2.5th - 97.5th percentiles. We performed Student's $t$-test or Mann-Whitney $\mathrm{U}$ test as appropriate in order to evaluate influence of sex on platelet parameters. Pearson's or Spearman's correlation coefficients was performed as appropriate to evaluate correlations between platelet parameters and correlation factors. Two-tailed $P$ values of less than 0.05 were set as statistical significance.

\section{Results}

Platelet parameters reference intervals

Totally 594 neonates were enrolled in present study. Demographic data are shown in Table 1. Several values were identified as outliers in platelet parameters and we excluded cases test-by-test in data analyses (see Fig. 1). 
Table 1 Demographic data of the subjects

\begin{tabular}{llll}
\hline Sex & Total & Male & Female \\
\hline $\mathrm{N}$ & 594 & 323 & 271 \\
Gestational age, days & $273(266-278)$ & $271(265-278)$ & $274(268-279)$ \\
Postnatal age, hours & $29(22-49)$ & $29(22-49)$ & $30(22-49)$ \\
\hline
\end{tabular}

Quantitative data were expressed as median (IQR Interquartile range)

Except for PLT, other platelet indices were not normally distributed. RIs for platelet parameters represent the central $95 \%$ out of all data (Table 2). As a result, capillary blood RI of PLT ranged from 152 to $464\left(\times 10^{9} / \mathrm{L}\right)$.

\section{Correlation factors}

Female neonates had higher capillary blood PLT values $\left(310( \pm 77) \times 10^{9} / \mathrm{L}\right)$ than male neonates $\left(299( \pm 77) \times 10^{9} /\right.$ L) but this difference was not statistically significant ( $p$ value $=0.082$ ). Expectedly, other platelet parameters were not significantly affected by sex (all $p$-values $>0.05$ ) (Table 2). In order to evaluate correlations between platelet parameters and gestational age (259 to 293 days of gestation) and postnatal age (12 to $81 \mathrm{~h}$ old), we performed Pearson's correlation coefficient in PLT and Spearman's correlation coefficient in platelet indices (Table 3). Significant negative correlations between gestational age and platelet parameters were observed ( $p$ - value $<0.05)$. However, in view of the low coefficients of correlation in PLT and PDW across gestational age, a biologic relationship between them is likely absent. Moreover, correlations between postnatal age and platelet parameters (except for PCT) were significant but very mild as all of absolute values of correlation coefficients were below 0.2 .

\section{Discussion}

RIs for platelet parameters are of great value in diagnosis and monitoring of various diseases in the neonatal period, particularly in the first days of life [3, 17, 18]. Previous studies on developing RIs for platelet parameters provided important information [8, 19-25]. However, the RIs were based on cord blood or venous blood in pre-term or term neonates [4-6, 26]. In present study, we presented the first RIs for platelet parameters using capillary blood in healthy term neonates.

Unfortunately, due to the difficulty to persuade parents to obtain venous blood samples from their healthy babies, we did not determine difference among various sampling sites. Early studies $[19,27]$ reported that significantly lower PLT values were found in capillary blood than venous blood. Their data proved the fact that capillary MPV values were higher than venous MPV values. Not surprisingly, PCT values were positively
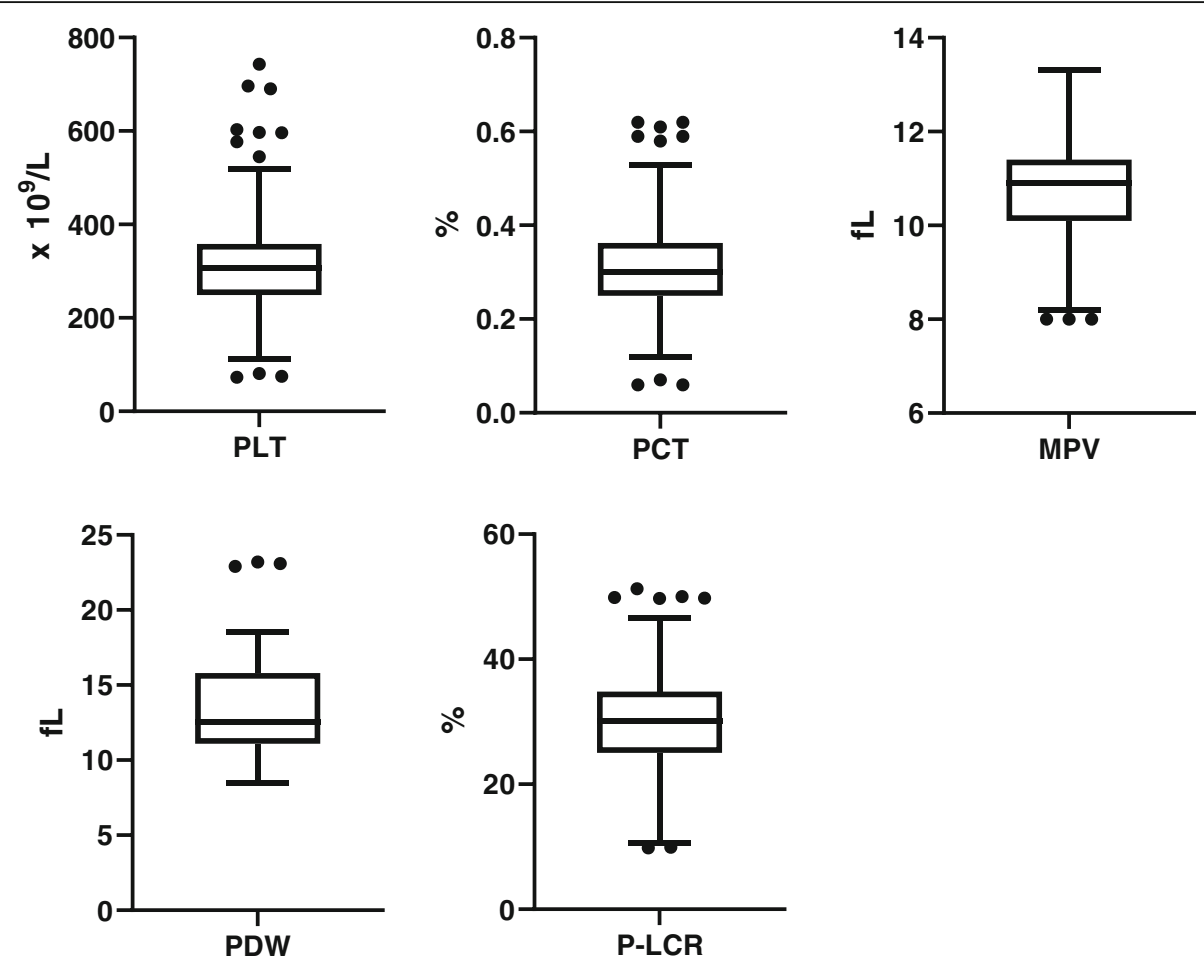

Fig. 1 The Box plot for platelet parameters data. The centre, the variability and the outliers are displayed. The following number of outliers was found: 11 for PLT, 9 for PCT, 3 for MPV, 3 for PDW, and 7 for P-LCR. Abbreviations: PLT, platelet count; PCT, plateletcrit; MPV, mean platelet volume; PDW, platelet size distribution width; P-LCR, platelet-large cell ratio 
Table 2 Capillary blood reference intervals for platelet parameters in healthy term neonates

\begin{tabular}{|c|c|c|c|c|c|}
\hline \multirow{2}{*}{$\begin{array}{l}\text { Platelet } \\
\text { parameters }\end{array}$} & \multicolumn{2}{|c|}{ Percentiles } & \multicolumn{3}{|c|}{ Demographic data } \\
\hline & 2.5 th & 97.5th & Total & Male & Female \\
\hline $\begin{array}{l}\mathrm{PLT} \\
\times 10^{9} / \mathrm{L}\end{array}$ & 152 & 464 & $304( \pm 77)$ & $299( \pm 77)$ & $310( \pm 77)$ \\
\hline $\mathrm{PCT}, \%$ & 0.18 & 0.46 & $0.30(0.26-0.36)$ & $0.30(0.25-0.36)$ & $0.31(0.26-0.37)$ \\
\hline MPV, fL & 8.3 & 12.6 & $10.9(10.1-11.4)$ & $10.9(10.2-11.4)$ & $10.8(10.0-11.4)$ \\
\hline PDW, fL & 9.4 & 17.1 & $12.5(11.1-15.8)$ & 12.5 (11.2-15.8) & $12.3(11.0-15.9)$ \\
\hline P-LCR, \% & 15.4 & 42.8 & $30.0(25.0-34.7)$ & $30.5(25.2-35.2)$ & $29.5(24.7-34.0)$ \\
\hline
\end{tabular}

Abbreviations: PLT Platelet count; PCT Plateletcrit; MPV Mean platelet volume; PDW Platelet size distribution width; $P$-LCR Platelet-large cell ratio. Data were expressed as either mean ( $S D \pm$ Standard deviation) or median (IQR Interquartile range)

correlated strongly with PLT values, while other platelet indices remained unchanged basically and did not obviously fluctuate along with PLT values [21]. Thus, a higher PCT value was also observed in venous blood compared with capillary blood. These data confirmed the effect of different sampling sites on platelet parameters in the neonatal period. Venous blood collection in neonates is full of challenges and time-consuming, which may make platelets relatively more likeness to activate and aggregate. Composition of capillary blood may be affected by local metabolic state as well as perfusion. Moreover, various extent of stress about extrusion on heel sampling sites may disturb the microcirculation and microenvironment and also affect the composition of capillary blood for that the samples may be mixed with an undetermined proportion of interstitial and intracellular fluids [26]. And in clinical practice, we should take neonatal sampling sites into consideration when choosing RIs for platelet parameters.

A recent study showed that neonatal age had a significant effect on the parameters regarding coagulation [28]. And we found a slight variation in PLT in the first days of life. Of note, a multicentre study recruiting a large neonate cohort [4] reported that PLT values changes with two peak sinusoids at 2-3 weeks and 6-7 weeks of postnatal age. On the other hand, in our current study, a very mild negative correlation was observed between PLT values and term gestational age (Pearson's correlation coefficient, $r=-0.143$ ), which may

Table 3 Correlations between platelet parameters and gestational age and postnatal age in healthy term neonates

\begin{tabular}{lllllll}
\hline Factor & & PLT & PCT & MPV & PDW & P-LCR \\
\hline Gestational age & $\mathrm{r}^{\mathrm{a}}$ & -0.143 & -0.237 & -0.255 & -0.161 & -0.206 \\
& $\mathrm{p}$ & 0.001 & $<0.001$ & $<0.001$ & $<0.001$ & $<0.001$ \\
Postnatal age & $\mathrm{r}^{\mathrm{a}}$ & -0.085 & 0.027 & 0.094 & 0.196 & 0.105 \\
& $\mathrm{p}$ & 0.041 & 0.509 & 0.023 & $<0.001$ & 0.011
\end{tabular}

Abbreviations: PLT Platelet count; PCT Plateletcrit; MPV Mean platelet volume; PDW Platelet size distribution width; $P$ - LCR Platelet-large cell ratio. ${ }^{\text {a }}$. Pearson's correlation coefficient was performed in PLT, and Spearman's correlation coefficient was performed in other platelet indices reflect a true absence of a biologic relationship. The multicentre study above and other previous studies [25, 29] reported that PLT values increased linearly with advancing gestational age. However, these studies $[4,30]$ are heterogeneous in nature because of both pre-term and term babies included and using variable blood samples, which may potentially lead to multiple confounding factors influencing their results and further resulting in a different observation with us.

The present study has some limitations. First, our cohort did not precisely determine the difference between various sampling sites because of the difficulty to obtain venous blood samples from healthy babies as described above. Secondly, as the neonates in our reference population aged from 12 to $84 \mathrm{~h}$, we cannot extrapolate how the RIs vary in the first $12 \mathrm{~h}$ of life or after postnatal age of $84 \mathrm{~h}$. Moreover, when the population is divided according to gestational age and postnatal age, the size of our study population does not meet the CLSI recommendation and therefore, we chose to report RIs for the combined population.

\section{Conclusions}

In conclusion, for the first time, the current study established capillary blood RIs for platelet parameters in the first days after birth in China. Furthermore, sex difference was of little clinical significance and therefore RIs for platelet parameters were combined for male and female neonates. And our findings showed values of platelet parameters changed with advancing gestational and postnatal age, which might provide clues for further multicentre investigations aimed at offering more accurate RIs for haematological parameters, in a larger population study.

\section{Abbreviations}

RIs: Reference intervals; CLSI: Clinical and laboratory standards institute; EDTA: K2-ethylenediaminetetraacetic acid; PLT: Platelet count; MPV: Mean platelet volume; PCT: Plateletcrit level; PDW: Platelet size distribution width; P-LCR: Platelet large cell ratio; SPSS: Statistical product and service solutions; SD: Standard deviation; IQR: Interquartile range 


\section{Acknowledgements}

We would like to thank all the subjects and their parents very much for their support and dedication, and the staff members of participating hospitals for their valuable cooperation in this research.

\section{Authors' contributions}

$\mathrm{QH}$ conceived and designed the research study, and reviewed the manuscript. LF and $\mathrm{YH}$ made contributions to the conception of the work and selected the qualified subjects. GL, CZ and JF analysed the neonatal blood samples. DC and $\mathrm{YH}$ analysed the data and wrote the manuscript. All authors (DC, YH, LF, GL, CZ, YH, JF and QH) have substantively revised the work and approved the final manuscript and submission.

\section{Funding}

The authors declare that they have no funding for the research reported.

\section{Availability of data and materials}

All data generated or analysed during this study are included in this published article. The datasets used and/or analysed during the current study are available from the corresponding author on reasonable request.

\section{Ethics approval and consent to participate}

Written informed consent was obtained from a parent or guardian for all subjects. The study was approved by The Human Ethics Committees of the Tongji Hospital, Tongji Medical College, Huazhong University of Science and Technology (TJ-IRB20190308).

\section{Consent for publication}

We have received informed consent from all subjects' parents or suitable proxies for publication of this paper and the written consent is held by our institution.

\section{Competing interests}

We have no conflicts of interest to disclose.

\section{Author details}

'Department of Paediatric Haematology and Oncology, Tongji Hospital, Tongji Medical College, Huazhong University of Science and Technology, Wuhan 430030, Hubei Province, People's Republic of China. ${ }^{2}$ Department of Paediatrics, Xiangyang Central Hospital, Xiangyang 441021, Hubei Province, People's Republic of China. ${ }^{3}$ Department of Gynaecology and Obstetrics, Tongji Hospital, Tongji Medical College, Huazhong University of Science and Technology, Wuhan 430030, Hubei Province, People's Republic of China. ${ }^{4}$ Department of Clinical Laboratory, Tongji Hospital, Tongji Medical College, Huazhong University of Science and Technology, Wuhan 430030, Hubei Province, People's Republic of China. ${ }^{5}$ Department of Gynaecology and Obstetrics, Xiangyang Central Hospital, Xiangyang 441021, Hubei Province, People's Republic of China. ${ }^{6}$ Department of Clinical Laboratory, Xiangyang Central Hospital, Xiangyang 441021, Hubei Province, People's Republic of China.

Received: 1 June 2020 Accepted: 6 October 2020

\section{Published online: 10 October 2020}

\section{References}

1. Jung B, Adeli K. Clinical laboratory reference intervals in pediatrics: the CALI PER initiative. Clin Biochem 2009; 42: 1589-1595. https://doi.https://doi.org/ 10.1016/j.clinbiochem.2009.06.025.

2. Alnor $A B$, Vinholt PJ. Paediatric reference intervals are heterogeneous and differ considerably in the classification of healthy paediatric blood samples. Eur J Pediatr 2019; 178: 963-971. https://doi.https://doi.org/10.1007/s00431019-03377-w.

3. Andres $\mathrm{O}$, Schulze $\mathrm{H}$, Speer CP. Platelets in neonates: central mediators in haemostasis, antimicrobial defence and inflammation. Thromb Haemost 2015; 113: 3-12. https://doi.https://doi.org/10.1160/TH14-05-0476.

4. Wiedmeier SE, Henry E, Sola-Visner MC, Christensen RD. Platelet reference ranges for neonates, defined using data from over 47,000 patients in a multihospital healthcare system. J Perinatol 2009; 29: 130-136. https://doi. https://doi.org/10.1038/jp.2008.141.

5. Grecu DS, Paulescu E. Quality assurance in the laboratory testing process: indirect estimation of the reference intervals for platelet parameters in neonates. Clin Biochem 2014; 47: 33-37. https://doi.https://doi.org/10.1016/j. clinbiochem.2014.07.002.

6. Chang YH, Yang SH, Wang TF, Lin TY, Yang KL, Chen SH. Complete blood count reference values of cord blood in Taiwan and the influence of gender and delivery route on them. Pediatr Neonatol 2011; 52: 155-160. https://doi.https://doi.org/10.1016/j.pedneo.2011.03.007.

7. Zierk J, Arzideh F, Rechenauer T, Haeckel R, Rascher W, Metzler M, et al.. Age- and sex-specific dynamics in 22 hematologic and biochemical analytes from birth to adolescence. Clin Chem 2015; 61: 964-973. https://doi.https:// doi.org/10.1373/clinchem.2015.239731.

8. Henry E, Christensen RD. Reference intervals in neonatal hematology. Clin Perinatol 2015; 42: 483-497. https://doi.https://doi.org/10.1016/j.clp.2015.04.005.

9. Paes B, Janes M, Vegh P, LaDuca F, Andrew M. A comparative study of heelstick devices for infant blood collection. Am J Dis Child. 1993;147:346-8.

10. Krleza JL. Nationwide survey of policies and practices related to capillary blood sampling in medical laboratories in Croatia. Biochem Med (Zagreb) 2014; 24: 350-358. https://doi.https://doi.org/10.11613/BM.2014.037.

11. Gallo S, Comeau K, Sharma A, Vanstone CA, Agellon S, Mitchell J, et al.. Redefining normal bone and mineral clinical biochemistry reference intervals for healthy infants in Canada. Clin Biochem 2014; 47: 27-32. https://doi.https://doi.org/10.1016/j.clinbiochem.2014.07.012.

12. Bell KJ, Gray R, Munns D, Petocz P, Howard G, Colagiuri S, et al.. Estimating insulin demand for protein-containing foods using the food insulin index. Eur J Clin Nutr 2014; 68: 1055-1059. https://doi.https://doi.org/10.1038/ejcn.2014.126.

13. lijima S, Baba T, Ueno D, Ohishi A. International normalized ratio testing with point-of-care coagulometer in healthy term neonates. BMC Pediatr 2014; 14: 179. https://doi.https://doi.org/10.1186/1471-2431-14-179.

14. Clinical and Laboratory Standards Institute CLSI. CLSI document C28-A3 (2008) Defining, Establishing, and Veryfying Reference Intervals in the Clinical Laboratory; Approved Guideline. Third ed. Wayne, PA: Clinical and Laboratory Standards Institute; 2008. p. C28-A3.

15. Wasiluk A. Thrombocytopoiesis in healthy term newborns. J Perinat Med 2005; 33: 252-254. https://doi.https://doi.org/10.1515/JPM.2005.046.

16. Kaito K, Otsubo H, Usui N, Yoshida M, Tanno J, Kurihara E, et al.. Platelet size deviation width, platelet large cell ratio, and mean platelet volume have sufficient sensitivity and specificity in the diagnosis of immune thrombocytopenia. Br J Haematol 2005; 128: 698-702. https://doi.https://doi. org/10.1111/j.1365-2141.2004.05357.x.

17. Coller BS. Historical perspective and future directions in platelet research. Thromb Haemost 2011; 9 Suppl 1: 374-395. https://doi.https://doi.org/10. 1111/j.1538-7836.2011.04356.x.

18. Christensen RD, Henry E, Del VA. Thrombocytosis and thrombocytopenia in the NICU: incidence, mechanisms and treatments. J Matern Fetal Neonatal Med 2012; 25 Suppl 4: 15-17. https://doi.https:/doi.org/10.3109/14767058.2012.715027.

19. Kayiran SM, Ozbek N, Turan M, Gurakan B. Significant differences between capillary and venous complete blood counts in the neonatal period. Clin Lab Haematol 2003; 25: 9-16. https://doi.https://doi.org/10.1046/j.1365-2257. 2003.00484.x.

20. Melioli G, Risso FM, Sannia A, Serra G, Bologna R, Mussap M, et al.. Reference values of blood cell counts in the first days of life. Front Biosci (Elite Ed) 2011; 3: 871-878. https://doi.https://doi.org/10.2741/e295.

21. Hoffmann JJ, van den Broek NM, Curvers J. Reference intervals of reticulated platelets and other platelet parameters and their associations. Arch Pathol Lab Med 2013; 137: 1635-1640. https://doi.https://doi.org/10.5858/arpa. 2012-0624-OA.

22. Effiong CE, Usanga EA, Mellits ED. Platelet count in healthy full-term Nigerian neonates. Trop Geogr Med. 1976;28:329-32.

23. Ozyurek E, Cetintas S, Ceylan T, Ogus E, Haberal A, Gurakan B, et al.. Complete blood count parameters for healthy, small-for-gestational-age, full-term newborns. Clin Lab Haematol 2006; 28: 97-104. https://doi.https:// doi.org/10.1111/j.1365-2257.2006.00767.x.

24. Biino G, Santimone I, Minelli C, Sorice R, Frongia B, Traglia M, et al.. Ageand sex-related variations in platelet count in Italy: a proposal of reference ranges based on 40987 subjects' data. PLoS One 2013; 8: e54289. https:// doi.https://doi.org/10.1371/journal.pone.0054289.

25. Glasser L, Sutton N, Schmeling M, Machan JT. A comprehensive study of umbilical cord blood cell developmental changes and reference ranges by gestation, gender and mode of delivery. J Perinatol 2015; 35: 469-475. https://doi.https://doi.org/10.1038/jp.2014.241.

26. Proytcheva MA. Issues in neonatal cellular analysis. Am J Clin Pathol 2009; 131: 560-573. https://doi.https://doi.org/10.1309/AJCPTHBJ4I4YGZQC. 
27. Ozbek N, Gurakan B, Kayiran SM. Complete blood cell counts in capillary and venous blood of healthy term newborns. Acta Haematol 2000; 103: 226-228. https://doi.https://doi.org/10.1159/000041056.

28. Liu Q, Xu C, Chen X, Wang J, Ke Z, Hu H. Establishing a reference range for thromboelastograph parameters in the neonatal period. Int J Lab Hematol 2019. https://doi.https://doi.org/10.1111/ij/h.13043.

29. Van den Hof MC, Nicolaides KH. Platelet count in normal, small, and anemic fetuses. Am J Obstet Gynecol 1990; 162: 735-739. https://doi.https://doi.org/ 10.1016/0002-9378(90)90997-I.

30. Rolim A, Lambert MA, Borges J, Abbas SA, Bordin JO, Langhi JD, et al.. Blood cells profile in umbilical cord of late preterm and term newborns. Rev Paul Pediatr 2019; 37: 264-274. https://doi.https://doi.org/10.1590/1984-0462/; 2019;37;3;00008

\section{Publisher's Note}

Springer Nature remains neutral with regard to jurisdictional claims in published maps and institutional affiliations.

Ready to submit your research? Choose BMC and benefit from:

- fast, convenient online submission

- thorough peer review by experienced researchers in your field

- rapid publication on acceptance

- support for research data, including large and complex data types

- gold Open Access which fosters wider collaboration and increased citations

- maximum visibility for your research: over $100 \mathrm{M}$ website views per year

At BMC, research is always in progress.

Learn more biomedcentral.com/submissions 